\title{
Controls on the oxygen penetration depth in Ediacaran-Paleozoic benthic ecosystems: A reactive-transport modeling study
}

\author{
ALISON T CRIBB ${ }^{1}$, SEBASTIAAN J VAN DE VELDE ${ }^{2,3}$, \\ WILLIAM M BERELSON ${ }^{1}$, DAVID J BOTTJER ${ }^{1}$ AND \\ FRANK A CORSETTI ${ }^{1}$ \\ ${ }^{1}$ University of Southern California \\ ${ }^{2}$ Université Libre de Bruxelles \\ ${ }^{3}$ Royal Belgian Institute of Natural Sciences \\ Presenting Author: cribb@usc.edu
}

The evolution of bioturbation during the Ediacaran Period was one of the most significant biotic innovations among macrofauna in Earth history. Early bioturbation is hypothesized to have increased oceanic sulfate concentrations, caused variability in atmospheric oxygen levels, and contributed to deeper sediment oxygenation. Increased sediment oxygenation purportedly triggered an expansion of the habitable benthic zone and increased tiering in benthic communities in the early Paleozoic. However, hypotheses that the evolution of bioturbation caused a deepening of the oxygen penetration depth (OPD) have generally not been tested for the different timing of the evolution of biomixing (solid sediment mixing) and bioirrigation (burrow ventilation) behaviors. Furthermore, important environmental changes such as carbon export efficiency and ocean oxygen concentrations have not been thoroughly investigated as potentially competing drivers of changes in the Paleozoic OPD.

To test hypotheses about what potentially allowed for oxygenation of the sediment in the Paleozoic, we developed a 1D sediment reactive-transport model simulating carbon, oxygen, nitrogen, and sulfur cycling. We used this model to conduct a series of experiments simulating the OPD at different levels of organic carbon flux, bottom water oxygen, and bioturbation (biomixing and bioirrigation). Modeling experiments were run from estimated Ediacaran boundary conditions of bottom water oxygen and organic matter fluxes to modern values. Each experiment was run with zero, weak (Ediacaran-like), and strong (late Paleozoic-like) bioturbation.

We find that increased organic matter flux and increased biomixing shallow the OPD. Furthermore, with weak levels of biomixing $\left(\mathrm{D}_{\mathrm{B}, 0}=1 \mathrm{~cm}^{2} / \mathrm{y}\right)$, bottom water oxygen concentrations must increase dramatically to deepen the OPD significantly. In contrast, bioirrigation deepens the OPD substantially, particularly in scenarios with lower organic matter flux. When simulating the evolution of bioturbation from the Ediacaran and through the Paleozoic, we find that the early development of weak biomixing shallows the OPD, and only the development of strong bioirrigation $\left(\alpha_{0}>300 \mathrm{y}^{-1}\right)$ allows the OPD to prebioturbation depths. As there is limited trace fossil evidence for burrow ventilation by large animals until the late Paleozoic, our results suggest that bioturbating macrofauna may have had a more delayed impact on the oxygenation of shallow marine sediments than previously hypothesized. 